\title{
Renewable Low-viscosity Dielectrics Based on Vegetable Oil Methyl Esters
}

\author{
Hui Yu*, Ping Yu* and Yunbai Luo ${ }^{\dagger}$
}

\begin{abstract}
Vegetable oil dielectrics have been used in transformers as green alternatives to mineral insulating oils for about twenty years, because of their advantages of non-toxic, biodegradability, and renewability. However, the viscosity of vegetable oils is more than 3 times of mineral oils, which means a poor heat dissipation capacity. To get low-viscosity dielectrics, transesterification and purification were performed to prepare vegetable oil methyl esters in this study. Electrical and physical properties were determined to investigate their potential as dielectrics. The results showed that the methyl ester products had good dielectric strengths, high water saturation and enough fire resistance. The viscosities $\left(\right.$ at $40^{\circ} \mathrm{C}$ ) were 0.2 times less than FR3 fluid, and 0.7 times less than mineral oil, which indicated superior cooling capacity as we expected. With the assistance of $0.5 \mathrm{wt} \%$ pour point depressants, canola oil methyl ester exhibited the lowest pour point $\left(-26^{\circ} \mathrm{C}\right)$ among the products which was lower than FR3 fluid $\left(-21^{\circ} \mathrm{C}\right)$ and $25 \#$ mineral oil $\left(-23^{\circ} \mathrm{C}\right)$. Thus, canola oil methyl ester was the best candidate as a low-viscosity vegetable oil-based dielectric. The low-viscosity fluid could extend the service life of transformers by its better cooling capacity compared with nature ester dielectrics.
\end{abstract}

Keywords: Insulating oil, Vegetable oil methyl ester, Low viscosity, Electrical and physical performance, Pour point depressants

\section{Introduction}

Insulating oil (or transformer oil) is a liquid dielectric that is widely used for electrical equipments, such as transformers, due to its insulation, cooling, and arc suppression effects $[1,2]$. For a century, mineral oil has firmly dominated the insulating oil market given its good insulation, heat dissipation properties, and inexpensive cost [3]. However, as a petroleum product, mineral oil is toxic, poorly biodegradable, and non-renewable. In the event of any leakage, mineral oil is prone to pollute the environment or leave hidden fire safety problems [4]. With the improvement of people's environmental awareness, the defects of mineral oil have been increasingly criticized [5]. Then, vegetable oil, a non-toxic, degradable, and renewable resource, was taken as a green substitute for mineral oil by researchers all over the world [6-9].

Until now, vegetable oil based dielectrics (natural esters) have been used in transformers for about twenty years [10]. There are mainly three products: Envirotemp FR $3 \circledR$ fluid, BIOTEMP ${ }^{\circledR}$ fluid and Midel ${ }^{\circledR}$ eN fluid, replacing mineral oil based products in the marketplace increasingly [11-13]. All the natural ester products have shown excellent electrical properties as liquid dielectrics. Moreover, their flash point is about $300{ }^{\circ} \mathrm{C}$, which is much higher than that of traditional mineral oil (about $150{ }^{\circ} \mathrm{C}$ ). Thus, vegetable

$\dagger$ Corresponding Author: College of Chemistry and Molecular Science, Wuhan University, PR China. (ybai@whu.edu.cn)

* College of Chemistry and Molecular Science, Wuhan University, PR China.

Received: August 2, 2016; Accepted: December 22, 2016 oil dielectrics are less flammable and much safer in term of fire hazard. However, compared with mineral insulating oils, natural ester dielectrics are weak in three aspects: pour point, oxidative stability, and viscosity, though pour point depressants (PPD) and antioxidants have been added in the products.

Firstly, since the average molecular weight of vegetable oil is about two to three times of that of mineral oil, the pour point of vegetable oil is higher than conventional mineral insulating oil. Even after adding PPD, the pour point of vegetable oil fails to reach $-30{ }^{\circ} \mathrm{C}$, which cannot meet the standard for mineral insulating oil according to IEC $60296\left(\leq-40{ }^{\circ} \mathrm{C}\right)$ [12]. Therefore, the usage of natural ester products in extremely cold weather becomes an issue. Secondly, due to the presence of unsaturated fatty acids in vegetable oil, allylic and bisallylic hydrogen atoms are easily removed to produce free radicals, which can significantly lower the oxidative stability $[14,15]$. Compared with mineral oil, the poor oxidative stability of vegetable oil makes it necessary to add more sufficient antioxidants. Some researchers even considered that vegetable oil-filled units should be sealed well to prevent the entering of air and moisture into the unit [16]. Thirdly, because of the three-chain structure and large molecular weight of triglyceride molecular, vegetable oil has a higher viscosity (FR3 fluid, $33 \mathrm{~mm}^{2} \cdot \mathrm{s}^{-1}$ at $40{ }^{\circ} \mathrm{C}$ ) than conventional mineral oil $\left(9.2 \mathrm{~mm}^{2} \cdot \mathrm{s}^{-1}\right.$ at $\left.40{ }^{\circ} \mathrm{C}\right)$ [17]. Viscosity is an important index of cooling performance for insulating oil as a coolant. Higher viscosity tends to lead to a higher working temperature of the transformer, which 
would accelerate the degradation of insulating oil and decomposition of insulating paper.

In current study, our work essentially concerned with the high viscosity of vegetable oil dielectrics. According to IEC 60076-7, the working life of paper insulation halves for every $6{ }^{\circ} \mathrm{C}$ increase in temperature. Thus, a lower viscosity of insulating oil always means a longer working life. Daniel et al. reported that the top oil temperature of transformer filled with vegetable oil (FR3 fluid) was approximately $4.4{ }^{\circ} \mathrm{C}$ higher than that of transformer filled with mineral oil, when loaded at 90 MVA [18]. The result showed an obvious difference in temperature caused by high viscosity of vegetable oil compared with mineral oil. Of course, working temperature is not the only factor affecting the service life of paper insulation. There was evidence that paper insulation in transformers aged more slowly in vegetable oil than mineral oil at the same temperature which was mainly linked to the higher water solubility of natural esters $[19,20]$. Thus, it's reasonable to consider that the high viscosity of vegetable oil will not lead to a shorter service lifetime of paper insulation compared with mineral oil. However, it doesn't mean that the high viscosity of vegetable oil should be ignored. For vegetable oil based transformer, if the viscosity of vegetable oil can be reduced, the working lifetime will be longer because of a lower operating temperature. Besides, the degradation of vegetable oil would also be slowed, which is an effective improvement for its poor oxidative stability. Moreover, low viscosity fluid could more effectively facilitate convective flow to cool the overheated windings and surfaces. Thus, the work on reducing viscosity of natural ester dielectrics is quite significant.

Some researchers have studied on this issue. Amanullah et al. used a viscosity modifier to reduce the viscosity of a special canola oil dielectric, from $40 \mathrm{~mm}^{2} \cdot \mathrm{s}^{-1}$ to 36 $\mathrm{mm}^{2} \cdot \mathrm{s}^{-1}$ (at $40{ }^{\circ} \mathrm{C}$ ) with the optimized modifier concentration of $0.5 \mathrm{wt} \%$, which was far away from the desirable level [21]. Then they applied for a patent that reducing the viscosity of vegetable oil dielectric by adding fatty acid alkyl esters as diluents, in a volume ratio of 40 : 60 to 60: 40 [22]. They reported that the viscosity of high oleic sunflower oil (HOSO) was reduced from $43 \mathrm{~mm}^{2} \cdot \mathrm{s}^{-1}$ to $15 \mathrm{~mm}^{2} \cdot \mathrm{s}^{-1}$ (at $40{ }^{\circ} \mathrm{C}$ ), when HOSO ethyl ester was blend with HOSO at $50 \mathrm{v} / \mathrm{v} \%$. The viscosity of blend was desirable compared with vegetable oil, but still higher than that of conventional mineral oil. Moreover, the patent did not mention the problem that the pour point of blend would increase. Actually, most fatty acid alkyl ester derivatives of vegetable oil exhibit obvious higher pour point than itself [23]. Kanoh et al. developed a low viscosity insulating oil using palm oil as a raw material, called PFAE (Palm Fatty Acid Ester) [24]. They prepared palm oil methyl ester firstly, which had a high pour point about $0{ }^{\circ} \mathrm{C}$. Then PFAE was synthesized by transesterification between palm oil methyl ester and another alkyl alcohol (maybe butyl alcohol), to improve the low temperature liquidity. The viscosity of PFAE was $5.06 \mathrm{~mm}^{2} \cdot \mathrm{s}^{-1}$ at $40{ }^{\circ} \mathrm{C}, 0.6$ times less than mineral oil, while the pour point is $-32.5{ }^{\circ} \mathrm{C}$ which means that the liquidity at low temperatures was better than natural ester products. PFAE had satisfactory performances, particularly in viscosity and pour point. However, the synthesis process is two-step which is more complex than one-step transesterification. And it may lead to a low yield which was not mentioned in their papers.

Based on the researches above, transesterification appears to be a feasible method to reduce the viscosity of natural esters. The low viscosity product of transesterification, vegetable oil alkyl ester, is also non-toxic, degradable and renewable, which has been used as biodiesel for a long time [25-27]. However, only a few studies on vegetable oil alkyl esters used as dielectrics have been reported.

The present study aims to investigate vegetable oil methyl ester, which is the easiest one to be synthesized in alkyl esters, as a low-viscosity vegetable oil-based insulating fluid. Considering that the properties (especially the pour point) of vegetable oil methyl esters may vary greatly with the fatty acid compositions, soybean, canola, peanut, and cottonseed oils, the four common vegetable oils in China, were chosen as raw materials. The electrical properties and basic physical properties of the prepared vegetable oil methyl esters were studied to verify their potential as dielectric medium. Commercialized vegetable insulating oil and domestic mineral insulating oil were selected for comparison. Based on the test results, four kinds of methyl ester products showed good electrical properties, high water saturation, expected viscosity which was lower than mineral oil, but poor liquidity at low temperatures which was even worse than natural ester dielectrics. In those methyl esters, canola oil methyl ester was the best candidate due to its relatively low pour point compared with others. To further improve the liquidity at low temperatures, a kind of PPD was used. The effects of PPD concentration on the pour point and other properties of canola oil methyl ester were evaluated. And the PPD concentration of $0.5 \mathrm{wt} \%$ was optimal, which could reduce the pour point of canola oil methyl ester from $-9{ }^{\circ} \mathrm{C}$ to $26{ }^{\circ} \mathrm{C}$ without affecting other properties much. With the help of PPD, canola oil methyl ester showed enough potential as a low-viscosity vegetable oil-based dielectric which could extend the service life of transformers compared with nature ester dielectrics.

\section{Materials and Methods}

\subsection{Materials}

Soybean, canola, and peanut oils (Jinlongyu, China) were obtained from a local supermarket. Cottonseed oil was obtained from local refineries (Hubei, China). Sodium hydroxide (AR), potassium hydroxide-ethanol standard 
solution (0.1 M), methanol (AR), phenolphthalein ( $\geq 98 \%$ ), diethyl ether (AR), Anhydrous magnesium sulphate (AR), ethanol (GR, 95\%), activated clay, and alkaline alumina (100-200 mesh) were purchased from Aladdin (Shanghai, China). Karl Fischer reagent was purchased from Concord (Tianjin, China). Envirotemp FR3 ${ }^{\circledR}$ fluid (FR3 or FR3 fluid) was purchased from Cargill (Minneapolis, USA), formerly developed by Cooper Industries (Houston, USA). Mineral insulating oil (25\#, Kunlun) was purchased from Petro China (Beijing, China). A PPD named CRISTOLPPD LX-150 was obtained from Pacific Ocean United Petro-Chemical Co. (Beijing, China), which was imported from India.

\subsection{Preparation of vegetable oil methyl esters}

Based on the results of previous experiments, in each synthesis of vegetable oil methyl ester, $200 \mathrm{~g}$ oil, a specific amount of methanol with molar ratio of alcohol to oil of $6: 1$, and a specific amount of sodium hydroxide (catalyst) with concentration in oil of $0.45 \mathrm{wt} \%$ were used. The reaction was conducted in a $500 \mathrm{ml}$ three-necked flask equipped with a condenser, a stirrer, and a thermometer. Firstly, methanol and sodium hydroxide were placed in the flask which was kept in a water bath at $60{ }^{\circ} \mathrm{C}$ and stirred. When the solids were dissolved completely, vegetable oil was slowly poured in the flask in a thin stream, with stirring. Then the reaction lasted for $60 \mathrm{~min}$ with stirring. Subsequently, the mixture was placed in a separatory funnel until two phases were obtained (one containing fatty acid methyl esters at the top and the other containing glycerin, sodium hydroxide, and methanol at the bottom). The methyl ester layer was obtained as the initial product by removing the glycerol layer from the bottom.

\subsection{Purification of vegetable oil methyl esters}

In the initial product, there were some ions, soap, a small amount of pigment, free fatty acid, moisture, and other impurities, which may seriously affect electrical properties $[12,28]$. Therefore, the purification of initial vegetable oil methyl ester was necessary for its usage as an insulating oil. The initial product was washed with deionized water until it became neutral and then dried with $10 \mathrm{~g}$ anhydrous magnesium sulfate. For further purification, it was treated with $3 \mathrm{wt} \%$ activated clay at $80{ }^{\circ} \mathrm{C}$ for $30 \mathrm{~min}$ and filtered and this process was repeated once. After bleaching, $4 \mathrm{wt} \%$ basic alumina was added and stirred with the product at $80{ }^{\circ} \mathrm{C}$ for $60 \mathrm{~min}$ to remove the free fatty acids and other acidic substances. Small particles were then filtered out with a microfiltration membrane (PVDF, $0.45 \mu \mathrm{m}$, Xingya, Shanghai, China). Finally, a rotary vacuum evaporator (RE-52CS, Yarong, Shanghai, China) was used to remove the volatiles and moisture from methyl ester. The final product was stored in a sealed amber bottle which was placed in a dry container.

\subsection{Gas Chromatography (GC)}

The fatty acid composition of each kind of vegetable oil methyl esters were analyzed by comparing each signal of fatty acid methyl esters (FAMEs) with that of mixture standards GLC-17A (C8-C24, Nu-Chek Prep Inc., Elysian, MN, USA) in GC (Varian 450-GC, Varian, USA), which was equipped with FID detector and VF-5MS column (30 $\mathrm{m}$ length, $0.25 \mathrm{~mm}$ i.d., $0.25 \mu \mathrm{m}$ film thickness, Varian, USA). The temperature program involved in holding the temperature at $150{ }^{\circ} \mathrm{C}$ for $1 \mathrm{~min}$, followed by heating to $250{ }^{\circ} \mathrm{C}$ at $10{ }^{\circ} \mathrm{C} / \mathrm{min}$ and then holding for $10 \mathrm{~min}$. The injector and the detector temperatures were held at $175^{\circ} \mathrm{C}$. A split ratio of 1:100 was employed.

The yield of the transesterification was determined by the total mass percent of FAMEs to the sample, showed results of, soybean oil: $97.70 \%$, canola oil: $95.89 \%$, peanut oil: $96.13 \%$, and cottonseed oil: $94.37 \%$.

\subsection{Electrical Properties}

\subsubsection{Breakdown voltage}

Breakdown voltage $\left(\mathrm{V}_{\mathrm{b}}\right)$ is the minimum voltage that causes a portion of an insulator to become electrically conductive, which is the most important index with respect to the insulating ability of dielectric materials. Measurements were carried out in $50 \mathrm{~Hz} \mathrm{AC}$, using partial sphere electrodes with the radius of $25 \mathrm{~mm}$ and the gap of $2.5 \mathrm{~mm}$, according to IEC 60156. The voltage was uniformly increased $(2.0 \pm 0.2 \mathrm{kV} / \mathrm{s})$ until breakdown occurred and the sample was stirred during all the tests. Then the value of voltage was recorded, and the sample was stirred for at least two minutes waiting for a repeated test. The $\mathrm{V}_{\mathrm{b}}$ value was the average of breakdown voltages in 6 repeated tests. All measurements were performed at room temperature.

\subsubsection{Relative permittivity, dissipation factor, and volume resistivity}

The relative permittivity of a material is its dielectric permittivity expressed as a ratio relative to the permittivity of vacuum. It expresses the force between two point charges in the material, and it is often used to indicate molecule polarity. Dissipation factor is a measure of the energy loss rate in a dielectric material. Volume resistivity is the opposition of a material to the flow of electric current. These properties were tested at $90{ }^{\circ} \mathrm{C}$ according to IEC 60247 using an AI-6000 tester (Huaian Keda Electric Co., China).

\subsection{Physical and chemical properties}

\subsubsection{Acid value and moisture content}

Acid value is the mass of potassium hydroxide that is required to neutralize $1 \mathrm{~g}$ of sample and measured 
according to ASTM D974. Moisture content was measured by coulometric Karl Fischer titration according to ASTM D1533.

High acid value and moisture content in insulating oil can lead to poor insulating performances and accelerate the degradation of oil and corrosion of metals in the transformer. Therefore, acid value and moisture content must be controlled below a limit. Due to the lack of standard for vegetable oil methyl ester used in electrical apparatus, ASTM D6871 (standard for vegetable oil as dielectric) was taken as a reference. Thus, acid value and moisture content of treated methyl ester should be less than $0.06 \mathrm{mgK}(\mathrm{OH}) \cdot \mathrm{g}^{-1}$ and $200 \mathrm{ppm}(\mathrm{mg} / \mathrm{kg})$, respectively, in this study.

\subsubsection{Pour point}

Pour point is defined as the lowest temperature at which the oil can flow when it is cooled, determining its adaptability at low temperature. In this study, the pour point of each sample was determined according to ASTM D97.

\subsubsection{Flash point}

Flash point is the lowest temperature at which the oil is fired with the help of an external flame. It indicates the safe working temperature of operation and volatility of the oil. High flash point considerably reduces the risk of fire in case of leakage or thermal fault. In this study, flash point was estimated by Pensky-Martens closed cup equipment according to ASTM D93.

\subsubsection{Viscosity}

Viscosity is a property arising from collisions between neighboring particles in a fluid moving at different velocities. It can be used to indicate the fluidity of a liquid. As a transformer coolant, insulating oil mainly absorbs and transports the heat generated by the electrical unit through convection or forced circulation. Thus, viscosity is an important index of cooling performance. In this study, the kinematic viscosity of each sample was determined according to ASTM D445.

\subsection{Statistical analysis}

All the experiments and measurements were performed in triplicate, except for $\mathrm{V}_{\mathrm{b}}$, which was repeated 6 times. The values were expressed as the mean \pm standard deviation.

\section{Results and Discussion}

\subsection{Fatty acid composition of vegetable oil methyl esters}

The fatty acid compositions of four kinds of vegetable
Table 1. Fatty acid composition of four kinds of vegetable oil methyl esters prepared (\%)

\begin{tabular}{ccccc}
\hline Fatty acid & Soybean & Canola & Peanut & Cottonseed \\
\hline Myristic (C14:0) & - & - & - & $0.5 \pm 0.0$ \\
Palmitic (C16:0) & $10.3 \pm 0.1$ & $6.0 \pm 0.1$ & $11.5 \pm 0.1$ & $26.4 \pm 0.2$ \\
Palmitoleic (C16:1) & $0.5 \pm 0.0$ & $0.2 \pm 0.0$ & - & $0.9 \pm 0.0$ \\
Stearic (C18:0) & $4.7 \pm 0.0$ & $2.2 \pm 0.0$ & $3.5 \pm 0.0$ & $1.5 \pm 0.0$ \\
Oleic (C18:1) & $17.1 \pm 0.4$ & $63.6 \pm 0.7$ & $32.9 \pm 0.4$ & $13.3 \pm 0.4$ \\
Linoleic (C18:2) & $59.2 \pm 0.5$ & $13.8 \pm 0.6$ & $45.8 \pm 0.5$ & $55.1 \pm 0.4$ \\
Linolenic (C18:3) & $7.7 \pm 0.1$ & $7.4 \pm 0.1$ & - & - \\
Arachidic (C20:0) & - & $0.6 \pm 0.0$ & $1.3 \pm 0.0$ & $0.4 \pm 0.0$ \\
Eicosenoic (C20:1) & $0.4 \pm 0.0$ & $2.1 \pm 0.0$ & $1.1 \pm 0.0$ & $0.8 \pm 0.1$ \\
Docosanoic (C22:0) & - & $0.3 \pm 0.0$ & $2.2 \pm 0.02$ & $0.3 \pm 0.0$ \\
Erucic (C22:1) & - & $3.9 \pm 0.0$ & $0.4 \pm 0.0$ & $0.6 \pm 0.0$ \\
Lignoceric (C24:0) & - & - & $1.4 \pm 0.0$ & - \\
\hline Saturated & $15.1 \pm 0.1$ & $9.0 \pm 0.1$ & $19.9 \pm 0.1$ & $29.1 \pm 0.2$ \\
Mono-unsaturated & $18.0 \pm 0.4$ & $69.8 \pm 0.7$ & $34.4 \pm 0.4$ & $15.7 \pm 0.4$ \\
Poly-unsaturated & $67.0 \pm 0.5$ & $21.2 \pm 0.6$ & $45.8 \pm 0.5$ & $55.1 \pm 0.4$ \\
\hline
\end{tabular}

oil methyl ester products were listed in Table 1. Unsaturated fatty acid exhibited the highest content in the four products, basically consisting of oleic acid or linoleic acid. Among the four products, soybean oil methyl ester showed the highest content of polyunsaturated fatty acid (primarily linoleic acid), canola oil methyl ester exhibited the highest content of monounsaturated fatty acid (basically oleic acid), and cottonseed oil methyl ester presented the highest content of saturated fatty acid (mainly palmitic acid). Peanut oil methyl ester showed the second highest content of saturated fatty acid (with a small amount of long-chain saturated fatty acids, such as arachidic, docosanoic, and lignoceric acids). According to the existing literature [29], transesterification or purification would not change the fatty acid compositions. The results were consistent with the findings of other studies [30-32].

\subsection{Moisture content and water saturation}

The moisture content can be expressed in terms of absolute value, or relative humidity which is a ratio of the dissolved water content in the oil relative to the maximum capacity of moisture that the oil can hold (water saturation). For liquid dielectrics with different water saturations, relative humidity is more suitable to compare the degree of dissolved water. And it was reported that the relative humidity in the insulating oil affected the breakdown voltage rather than the absolute moisture content [33].

However, there is not a standard for the determination of water saturation. A conventional way is to make a saturated oil sample and then measure the absolute moisture content [34]. In this study, each sample was mixed with an equal volume of water with stirring. Every once in a while, stop stirring. The moisture content was measured after the mixture stratified completely. The sample was considered to be saturated when the value changed little in $24 \mathrm{~h}$.

The results of moisture content and water saturation were shown in Table 2. The water saturation values of FR3 and mineral oil were basically consistent with the values 
Table 2. Moisture content and water saturation of samples

\begin{tabular}{cccc}
\hline Samples & $\begin{array}{c}\text { Absolute moisture } \\
\text { content }\left(\mathrm{ppm}^{\mathrm{a}}\right)\end{array}$ & $\begin{array}{c}\text { Water saturation at } \\
20{ }^{\circ} \mathrm{C}\left(\mathrm{ppm}^{\mathrm{a}}\right) \\
\text { Soybean }\end{array}$ & $\begin{array}{c}\text { Relative humidity } \\
\text { at } 20{ }^{\circ} \mathrm{C}(\%)\end{array}$ \\
Canola & $8.9 \pm 1.1$ & $1243.0 \pm 65.4$ & 1.1 \\
Peanut & $14.2 \pm 0.9$ & $1226.9 \pm 64.3$ & 0.7 \\
Cottonseed & $8.1 \pm 1.0$ & $1236.5 \pm 68.6$ & 1.1 \\
FR3 fluid & $56.5 \pm 2.9$ & $1150.2 \pm 51.7$ & 0.6 \\
Mineral oil & $10.5 \pm 0.7$ & $59.3 \pm 2.7$ & 4.9 \\
\hline
\end{tabular}

${ }^{\mathrm{a}} \mathrm{ppm}=\mathrm{mg} / \mathrm{kg}$.

mentioned in the literature [35]. The water saturations of four kinds of methyl ester products and FR3 were approximately 20 times of that of mineral oil. The huge difference may be caused by the presence of ester groups in methyl esters and natural esters which were hydrophilic and polar groups. A little higher water saturations of methyl esters than FR3 could be explained by the greater polarity of methyl ester molecules than triglyceride molecules, which was closer to water. In previous studies on natural ester dielectrics, high water saturation of vegetable oil was considered to be a beneficial property which can make it absorb more water from insulating paper than mineral oil, to slow the aging rate of insulating paper $[19,36]$. Besides, compared with mineral oil, the moisture in vegetable insulating oil system had a smaller influence on the dielectric strength, because the relative humidity changed very little [37]. The advantages above could also be expected when vegetable oil methyl esters used as dielectrics, because their water saturations were even higher than those of nature esters.

It was reported that low levels of moisture would not affect the breakdown voltage of insulating oils [33]. However, there were no standards to judge whether the moisture contents of methyl esters were low enough. Taking nature esters as references, the breakdown voltage of FR3 fell at around the moisture content of $300 \mathrm{ppm}$, which was specified a maximum moisture content of 200 ppm in ASTM D6871 [35]. Thus, the moisture content of FR3 sample in this study was at an acceptable level, while the absolute moisture contents and relative humidity of four methyl ester products was significantly lower. The differences of moisture contents between methyl esters and FR3 could be attributed to that methyl esters were measured in a short period of time after purification process, while FR3 had been placed for some time since being purchased.

\subsection{Acid value}

In traditional mineral insulating oil, acidity was very low and increased mainly due to the slow oxidation of mineral oil. Thus, acid value was used to characterize the quality and chemical stability of mineral oils. Compared with
Table 3. Acid value of samples $\left(\left(\mathrm{mg} \mathrm{K}(\mathrm{OH}) \cdot \mathrm{g}^{-1}\right)\right)$

\begin{tabular}{ccccccc}
\hline Property & Soybean & Canola & Cottonseed & Peanut & $\begin{array}{c}\text { FR3 } \\
\text { fluid }\end{array}$ & $\begin{array}{c}\text { Mineral } \\
\text { oil }\end{array}$ \\
\hline Acid value & $<0.06$ & $<0.06$ & $<0.06$ & $<0.06$ & $<0.06$ & $<0.01$ \\
\hline
\end{tabular}

Table 4. Breakdown voltage of samples

\begin{tabular}{cccc}
\hline Samples & Mean $(\mathrm{kV})$ & $\begin{array}{c}\text { Standard deviation } \\
(\mathrm{kV})\end{array}$ & $\begin{array}{c}\text { Relative standard } \\
\text { deviation }(\%)\end{array}$ \\
\hline Soybean & 60.5 & 6.9 & 11.4 \\
Canola & 54.9 & 6.8 & 12.4 \\
Peanut & 59.1 & 6.5 & 11.0 \\
Cottonseed & 61.3 & 7.4 & 12.0 \\
FR3 fluid & 54.4 & 6.5 & 11.9 \\
Mineral oil & 49.0 & 5.1 & 10.4 \\
\hline
\end{tabular}

mineral oils, acid values of natural esters and methyl esters were higher under normal condition, because they could hydrolyze easily to generate free fatty acids in the presence of only a little moisture [38]. Due to the hygroscopicity of natural esters and methyl esters, the reduction of acidity would also be more difficult than that in mineral oils. As shown in Table 3, the acid values of four purified methyl ester products could meet the requirements in ASTM D7871 $\left(\leq 0.06 \mathrm{mgK}(\mathrm{OH}) \cdot \mathrm{g}^{-1}\right)$ for natural ester dielectrics, but could not reach the level of mineral oil in previous experiments.

\subsection{Breakdown voltage}

The results of breakdown voltage were listed in Table 4 . The relative standard deviations of all samples were approximately $10 \%$, indicating that the breakdown voltage was an parameter with a strong dispersion. The means of four kinds of methyl ester products and FR3 were 5.4- 12.3 $\mathrm{kV}$ higher than that of mineral oil, while the standard deviations were also higher about $2 \mathrm{kV}$. It indicated that the average dielectric strengths of methyl esters and FR3 were higher than mineral oil, but a little more dispersed. A similar result was reported on comparing the breakdown voltages between FR3 and mineral oil [39]. Although the significant differences can not be determined without enough data or significance analysis such as t-test, it could be sure that dielectric strengths of vegetable oil methyl esters were no worse than FR3 or mineral insulating oil. It indicated that vegetable oil methyl oils had enough insulating property as dielectrics.

It should be noted that all insulating liquids would be processed through degassing, dehydrating and filtering under vacuum to enhance dielectric properties before used in a transformer [40]. However methyl ester products were only treated in purification process in the lab, with the FR3 and mineral oil samples without any treatment after purchased. Thus, the measured values of breakdown voltage in this work could be a little lower than data of oils in a transformer. 


\subsection{Relative permittivity, dissipation factor, and volume resistivity}

Relative permittivity, dissipation factor, and volume resistivity are the electrical properties related to the polarity of liquid dielectrics. When the polarity is greater, relative permittivity and dissipation factor are bigger, whereas the volume resistivity is smaller. In these properties, dissipation factor and volume resistivity would be changed significantly only by a small amount of polar impurities or by-products. Thus, they are good indicators for determining any contaminations in insulating oils, particularly mineral oils which are non-polar. Conversely, the relative permittivity is relatively stable so that it could be used to identify the type of dielectrics.

The results of relative permittivity in Table 5 showed that the polarity of methyl esters and FR3 obviously greater than that of mineral oil, while the polarity of methyl esters is a little greater than that of FR3. The results of dissipation factor and volume resistivity showed a consistency with the differences of polarity. The dissipation factor and volume resistivity of methyl esters were significantly weaker than that of FR3, though their relative permittivity values were closed to each other. It may be due to the content differences of polar impurities between methyl esters and FR3 , such as free fatty acids [41]. Among four kinds of methyl ester products, canola oil methyl ester was significantly different from others with lower relative permittivity, lower dissipation factor, and high volume resistivity. It was due to comprehensive influence of differences on purity and polarity.

As a result of the differences mainly in polarity, the relative permittivity, dissipation factor, and volume resistivity of methyl esters were quite different from those of FR3 or mineral oil. A new standard for evaluation on these electrical properties of vegetable oil methyl ester dielectrics was needed.

Table 5. Relative permittivity, dissipation factor, and volume resistivity of samples at $90{ }^{\circ} \mathrm{C}$

\begin{tabular}{cccc}
\hline Samples & $\begin{array}{c}\text { Relative } \\
\text { permittivity }\end{array}$ & $\begin{array}{c}\text { Dissipation } \\
\text { factor }(\%)\end{array}$ & $\begin{array}{c}\text { Volume resistivity } \\
\left(10^{9} \Omega \cdot \mathrm{m}\right)\end{array}$ \\
\hline Soybean & $2.865 \pm 0.001$ & $2.87 \pm 0.04$ & $5.3 \pm 0.1$ \\
Canola & $2.826 \pm 0.002$ & $1.16 \pm 0.01$ & $21.8 \pm 0.2$ \\
Cottonseed & $2.880 \pm 0.001$ & $2.79 \pm 0.04$ & $6.4 \pm 0.1$ \\
Peanut & $2.865 \pm 0.001$ & $4.20 \pm 0.06$ & $5.3 \pm 0.0$ \\
FR3 fluid & $2.800 \pm 0.000$ & $0.69 \pm 0.00$ & $86.6 \pm 0.5$ \\
Mineral oil & $2.322 \pm 0.001$ & $0.10 \pm 0.00$ & $124.0 \pm 1.7$ \\
\hline
\end{tabular}

Table 6. Physical properties of samples

\begin{tabular}{cccc}
\hline Samples & $\begin{array}{c}\text { Flash point } \\
\text { (closed cup) }\left({ }^{\circ} \mathrm{C}\right)\end{array}$ & $\begin{array}{c}\text { Kinematic viscosity } \\
\text { at } 40{ }^{\circ} \mathrm{C}\left(\mathrm{mm}^{2} \cdot \mathrm{s}^{-1}\right)\end{array}$ & $\begin{array}{c}\text { Pour point } \\
\left({ }^{\circ} \mathrm{C}\right)\end{array}$ \\
\hline Soybean & $175 \pm 1$ & $4.38 \pm 0.01$ & $-3 \pm 0$ \\
Canola & $163 \pm 0$ & $4.95 \pm 0.00$ & $-9 \pm 0$ \\
Cottonseed & $160 \pm 0$ & $5.32 \pm 0.00$ & $-4 \pm 0$ \\
Peanut & $181 \pm 2$ & $5.12 \pm 0.00$ & $7 \pm 0$ \\
FR3 fluid & $280 \pm 1$ & $34.96 \pm 0.03$ & $-21 \pm 0$ \\
Mineral oil & $145 \pm 1$ & $7.51 \pm 0.01$ & $-23 \pm 0$ \\
\hline
\end{tabular}

\subsection{Physical properties}

The physical property results of four methyl ester products were listed in Table 6. Pour point and kinematic viscosity values were consistent with findings of studies on biodiesel [42-44], whereas flash point values were a little higher, which may be due to higher purity of methyl esters in this work.

\subsubsection{Flash point}

The flash points of fours methyl ester products ranged from $160{ }^{\circ} \mathrm{C}$ to $181{ }^{\circ} \mathrm{C}$, which were about $100{ }^{\circ} \mathrm{C}$ lower than that of FR3, but approximately $20{ }^{\circ} \mathrm{C}$ higher than that of mineral oil. It indicated that the flash point of vegetable oil methyl eater could meet the requirements of conventional insulating oil (mineral oil), though could not be used as less flammable fluid like natural ester dielectrics (FR3).

\subsubsection{Viscosity}

The kinematic viscosities (at $40{ }^{\circ} \mathrm{C}$ ) of four methyl ester products were ranged from $4.38 \mathrm{~mm}^{2} \cdot \mathrm{s}^{-1}$ to $5.32 \mathrm{~mm}^{2} \cdot \mathrm{s}^{-1}$, which were 0.2 times less than FR3, and 0.7 times less than mineral oil. Note that the working temperature of transformer would exceed above $40{ }^{\circ} \mathrm{C}$ [18], while the viscosities of different dielectrics may decrease in different degrees with increasing temperature. Thus, the viscosities at $60{ }^{\circ} \mathrm{C}$ and $80{ }^{\circ} \mathrm{C}$ were also investigated and showed similar results in Fig. 1. The low viscosity of vegetable oil methyl esters was satisfactory as we expected, indicating an excellent cooling performance compared to nature ester dielectrics.

\subsubsection{Pour point}

Pour point values of four methyl ester products showed significant differences due to the differences in fatty acid compositions, especially the type and content of long-chain

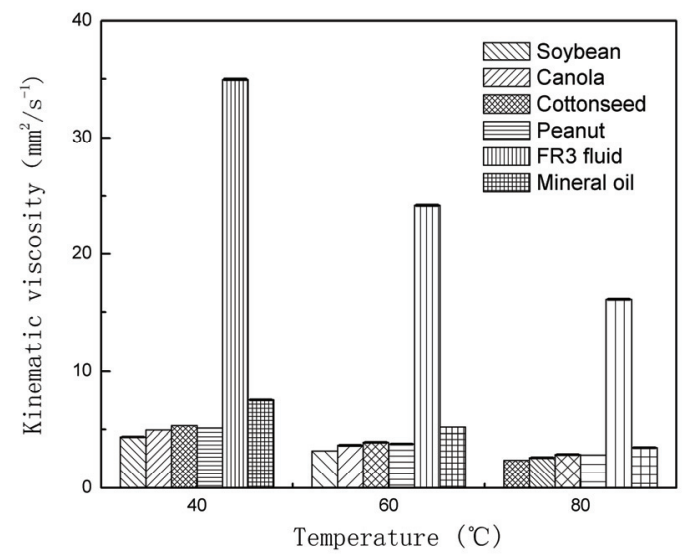

Fig. 1. Kinematic viscosity of samples at $40{ }^{\circ} \mathrm{C}, 60{ }^{\circ} \mathrm{C}$, and $80{ }^{\circ} \mathrm{C}$ 
saturated fatty acid. The pour point of peanut ester was the highest $\left(7^{\circ} \mathrm{C}\right)$ because peanut oil contained the most long-chain saturated fatty acids, such as arachidic (C20), docosanoic (C22), and lignoceric (C24) acids. The pour point of canola ester was the lowest $\left(-9{ }^{\circ} \mathrm{C}\right)$ because it had the lowest saturated fatty acid content $(9.0 \mathrm{wt} \%)$, which was primarily composed of palmitic (C16) and stearic acids (C18).

FR3 had a significantly lower pour point than vegetable oil methyl esters about $18{ }^{\circ} \mathrm{C}$ to $28{ }^{\circ} \mathrm{C}$, which can be explained in three aspects. Firstly, the pour point of vegetable oil was lower than its methyl ester derivative with the same fatty acid composition, due to the differences in molecular structure. Secondly, the pour point of vegetable oil methyl esters varied with fatty acid compositions, which had been discussed above. Thirdly, some kind of PPD may have been added in FR3 to lower its pour point, which could not be confirmed from related literatures.

Though the pour point values of FR3 $\left(-21^{\circ} \mathrm{C}\right)$ and $25 \#$ mineral oil $\left(-23{ }^{\circ} \mathrm{C}\right)$ can not meet this standard for classical mineral insulating oils $\left(\leq-40{ }^{\circ} \mathrm{C}\right)$ in IEC 60296, they can be applied in the most area of China even in winter because the temperatures rarely fall below $-20{ }^{\circ} \mathrm{C}$. By contrast, the low temperature fluidities of four methyl ester products were so poor that they could not be used when temperatures fall below $-10{ }^{\circ} \mathrm{C}$. Thus, the low temperature fluidity of vegetable oil methyl esters must be improved, for their usage as dielectrics even in China. A kind of PPD would be used to lower the pour points of vegetable oil methyl esters. For optimization, canola oil methyl eater was chosen as candidate, which had the lowest pour point among the four kinds of methyl ester products.

\subsection{Effect of PPD on vegetable oil methyl esters}

PPD is a common additive used in mineral oils, vegetable oils and biodiesels, to improve their lowtemperature flow behaviors by delaying or suppressing the nucleation and crystal growth stages during the wax crystallization process. There are many kinds of PPD with different chemical compositions designed for different oils. In this study, three issues need to be considered to investigate suitable PPD for vegetable oil methyl esters: effect of reducing the pour point, impact on other important properties, toxicity \& biodegradability.

Oommen et al. reported that a kind of polymethylacrylate (PMA) PPD was used in their product, BIOTEMP fluid. The pour point could be depressed by ten degrees without affecting the conductivity, when PPD was used below $1 \mathrm{wt} \%$. And the product was tested to be a nontoxic and biodegradable liquid [45]. It indicated that PMA PPD may be a suitable candidate for vegetable oil methyl esters which was nontoxic and biodegradable when the concentration was below $1 \mathrm{wt} \%$. Thus, a commercialized PMA PPD, named CRISTOL-PPD LX-150, was used in canola oil methyl ester.
Table 7. Effect of PPD on four kinds of vegetable oil methyl esters prepared.

\begin{tabular}{ccc}
\hline \multirow{2}{*}{ Methyl esters } & \multicolumn{2}{c}{ Pour point $\left({ }^{\circ} \mathrm{C}\right)$} \\
\cline { 2 - 3 } & Neat oil & With $0.5 \mathrm{wt} \%$ PPD \\
\hline Soybean & $-3 \pm 0$ & $-13 \pm 0$ \\
Canola & $-9 \pm 0$ & $-26 \pm 0$ \\
Cottonseed & $-4 \pm 0$ & $-9 \pm 0$ \\
Peanut & $7 \pm 0$ & $-9 \pm 0$ \\
\hline
\end{tabular}

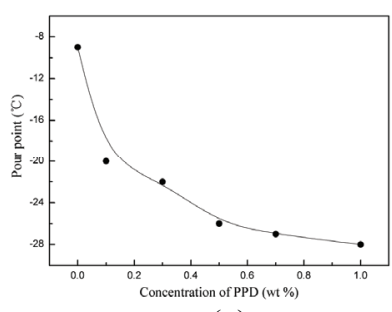

(a)

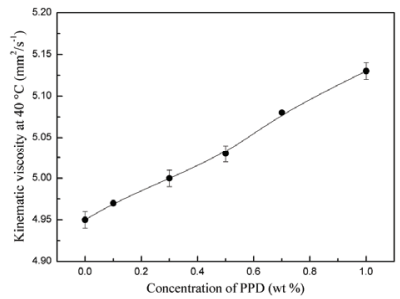

(c)

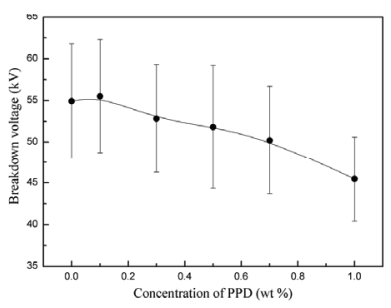

(b)

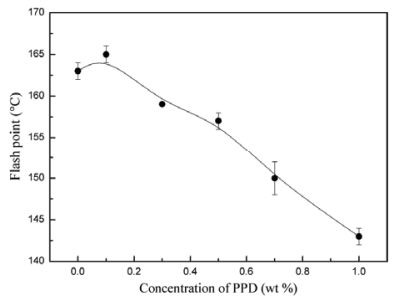

(d)

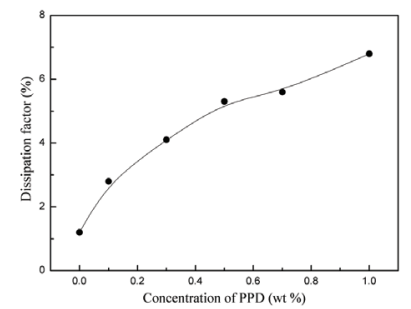

(e)

Fig. 2. Effects of PPD concentration on properties of canola oil methyl ester : (a) Pour point; (b) Breakdown voltage; (c) Kinematic viscosity; (d) Flash point; (e) dissipation factor

As shown in Fig. 2(a), the pour point of canola oil methyl ester dropped sharply when the dosage was $0-$ $0.5 \mathrm{wt} \%$, from $-9{ }^{\circ} \mathrm{C}$ to $-26{ }^{\circ} \mathrm{C}$; the effect leveled off above $0.5 \mathrm{wt} \%$, from $-26{ }^{\circ} \mathrm{C}$ to $-28{ }^{\circ} \mathrm{C}$. The results in Fig. 2(b)Fig. 2(d) showed little changes below approximately $5 \%$ on breakdown voltage, flash point, and viscosity when the concentration of PPD was below $0.5 \mathrm{wt} \%$. Fig. 2(e) showed a significant increase in dissipation factor, from $1.16 \%$ to $6.78 \%$, with increasing PPD concentration up to $1.0 \mathrm{wt} \%$. It indicated that PMA PPD was strongly polar, and may pose a risk to dissipation factor at high concentration. For comprehensive consideration, the suitable amount of PPD in the present study was $0.5 \mathrm{wt} \%$.

With the addition of $0.5 \mathrm{wt} \%$ PMA PPD in four methyl ester products, the most striking results were presented by canola ester/PPD $\left(-9{ }^{\circ} \mathrm{C}\right.$ to $\left.-26{ }^{\circ} \mathrm{C}\right)$ and peanut 
ester/PPD $\left(7{ }^{\circ} \mathrm{C}\right.$ to $\left.-9{ }^{\circ} \mathrm{C}\right)$, as shown in Table 7 . By contrast, the worst result was for the cottonseed ester/PPD $\left(-4{ }^{\circ} \mathrm{C}\right)$ in comparison with neat oil $\left(-9^{\circ} \mathrm{C}\right)$. For soybean ester $\left(-3{ }^{\circ} \mathrm{C}\right.$ to $\left.-13{ }^{\circ} \mathrm{C}\right)$, the effect of PPD was slightly better. Note that the different effects of PPD on pour points of vegetable oil methyl esters were due to the specific composition of PPD and fatty acid compositions of methyl esters. Not all kinds of PMA PPD could achieve the same effect. The results showed that canola oil methyl ester had the best low temperature fluidity $\left(-26^{\circ} \mathrm{C}\right)$ among the four kinds of methyl ester products when $0.5 \mathrm{wt} \%$ CRISTOLPPD LX-150 was added, which was a little better than FR3 $\left(-21{ }^{\circ} \mathrm{C}\right)$ and $25 \#$ mineral insulating oil $\left(-23{ }^{\circ} \mathrm{C}\right)$.

\section{Conclusion}

In the present study, four kinds of vegetable oil methyl esters were prepared from soybean, peanut, canola, and cottonseed oils by conventional base-catalyzed transesterification, and then further purified to improve their electrical properties. Compared with FR3 fluid and 25\# mineral oil, vegetable oil methyl esters showed low viscosities at $40{ }^{\circ} \mathrm{C}, 0.2$ times less than FR3, and 0.7 times less than mineral oil, which indicated superior liquidity and cooling capacity. The breakdown voltages of methyl esters (means ranged from $54.9 \mathrm{kV}$ to $61.3 \mathrm{kV}$ ) were no lower than FR3 (54.4 kV) or mineral insulating oil (49.0 $\mathrm{kV}$ ), indicating good dielectric strengths. The flash points of vegetable oil methyl esters were approximately $20^{\circ} \mathrm{C}$ higher than mineral oil, demonstrated enough fire resistance as common insulating oils. The biggest flaw of vegetable oil methyl esters is their poor low temperature fluidity characterized by high pour point. Fortunately, among the four kinds methyl esters, canola oil methyl ester had the lowest pour point of $-26{ }^{\circ} \mathrm{C}$ with the assistance of $0.5 \mathrm{wt} \%$ PMA PPD (CRISTOL-PPD LX-150), without much affects on other properties. The pour point of canola ester/PPD was lower than FR3 $\left(-21^{\circ} \mathrm{C}\right)$ and $25 \#$ mineral insulating oil $\left(-23{ }^{\circ} \mathrm{C}\right)$, which meant an applicability in the most area of China even in winter, though still far away from the standard for conventional mineral insulating oil $\left(\leq-40{ }^{\circ} \mathrm{C}\right)$.

The results of electrical and physical properties showed that canola oil methyl ester had enough potential as a lowviscosity vegetable oil-based dielectric. This low- viscosity fluid would extend the service life of the transformer by its better cooling capacity and high water saturation compared with nature ester dielectrics. Besides, it was also a green substitute for fossil energy as a derivative of vegetable oil, which is non-toxic, degradable, and renewable.

However, lots of further investigations are needed for the application and generalization of the low- viscosity fluid, such as the oxidation stability, the influence of antioxidants, aging properties, gassing properties, compatibility with transformer materials. Besides, some expected advantages need to be verified in real cases. Moreover, the evaluation standard for this fluid need to be developed which is different from that of mineral insulating oils or natural ester dielectrics.

\section{References}

[1] D. Cao, Chromatographic analysis and fault diagnosis for transformer oil, China Electric Power Press, 2010.

[2] M. Heathcote, J \& P transformer book, Newnes, 2011.

[3] T.O. Rouse, "Mineral insulating oil in transformers," IEEE Electrical Insulation Magazine, vol. 14, no. 3, pp. 6-16, 1998.

[4] Y. Bertrand, and L. Hoang, "Vegetable oils as substitute for mineral insulating oils in medium-voltage equipments," CIGRE Reports, D1-202, 2004.

[5] S.Z. Erhan, and S. Asadauskas, "Lubricant basestocks from vegetable oils," Industrial crops and products, vol. 11, no. 2, pp. 277-282, 2000.

[6] S. Boyde, "Green lubricants. Environmental benefits and impacts of lubrication," Green Chemistry, vol. 4, no. 4, pp. 293-307, 2002.

[7] M. Shinke, K. Miyazato, T. Tada, Y. Takeuchi, Y. Nakagami, R. Shimizu, M. Kosaka, and M. Wada, "Fundamental studies on development of environment friendly vegetable oil filled transformer," IEEJ Transactions on Power and Energy, vol. 123, pp. 187-193, 2003.

[8] M.A.G. Martins, "Vegetable oils, an alternative to mineral oil for power transformers-experimental study of paper aging in vegetable oil versus mineral oil," IEEE Electrical Insulation Magazine, vol. 6, no. 26, pp. 7-13, 2010.

[9] N. Azis, J. Jasni, M.Z.A. Ab Kadir, and M.N. Mohtar, "Suitability of palm based oil as dielectric insulating fluid in transformers," Journal of Electrical Engineering \& Technology, vol. 9, no. 2, pp. 662-669, 2014.

[10] C. Watkins, "Transforming the transformer industry," Inform, vol. 19, no. 8, pp. 524-526, 2008.

[11] C. P. McShane, "Vegetable-oil-based dielectric coolants," IEEE Industry Applications Magazine, vol. 8, no. 3, pp. 34-41, 2002.

[12] T. Oommen, "Vegetable oils for liquid-filled transformers," IEEE Electrical Insulation Magazine, vol. 18, no. 1, pp. 6-11, 2002.

[13] S. Tenbohlen, and M. Koch, "Aging performance and moisture solubility of vegetable oils for power transformers," IEEE Transactions on Power Delivery, vol. 25, no. 2, pp. 825-830, 2010.

[14] F.M.T. Luna, B.S. Rocha, E.M. Rola, M.C. Albuquerque, D.C. Azevedo, and C.L. Cavalcante, "Assessment of biodegradability and oxidation stability of mineral, vegetable and synthetic oil samples," Industrial Crops and Products, vol. 33, no. 3, pp. 579-583, 2011.

[15] S.Z. Erhan, B.K. Sharma, and J.M. Perez, "Oxidation 
and low temperature stability of vegetable oil-based lubricants," Industrial Crops and Products, vol. 24, no. 3, pp. 292-299, 2006.

[16] M. Rafiq, Y. Lv, Y. Zhou, K. Ma, W. Wang, C. Li, and Q. Wang, "Use of vegetable oils as transformer oils-a review," Renewable and Sustainable Energy Reviews, vol. 52, pp. 308-324, 2015.

[17] C.P. McShane, "Relative properties of the new combustion-resist vegetable-oil-based dielectric coolants for distribution and power transformers," IEEE Transactions on industry applications, vol. 37, no. 4, pp. 1132-1139, 2001.

[18] D. Martin, J. Wijaya, N. Lelekakis, D. Susa, and N. Heyward, "Thermal analysis of two transformers filled with different oils," IEEE Electrical Insulation Magazine, vol. 1, no. 30, pp. 39-45, 2014.

[19] C.P. McShane, K.J. Rapp, J.L. Corkran, G.A. Gauger, and J. Luksich, "Aging of paper insulation in natural ester dielectric fluid," in Transmission and Distribution Conference and Exposition, 2001 IEEE/PES, 2001.

[20] S. Liang, R. Liao, L. Yang, J. Li, C. Sun, and H. Sun, "Thermal aging characteristics of natural ester impregnated Kraft paper and thermally upgraded paper insulation," in High Voltage Engineering and Application, 2008. ICHVE 2008. International Conference on, 2008.

[21] M. Amanullah, S.M. Islam, S. Chami, and G. Ienco, "Analyses of physical characteristics of vegetable oils as an alternative source to mineral oil-based dielectric fluid," in IEEE International Conference on Dielectric Liquids, 2005. ICDL 2005.

[22] M. Amanullah, S.M. Islam, S. Chami, and G. Ienco, "Low viscosity vegetable oil-based dielectric fluids," Google Patents, 2007.

[23] D. Y. Leung, X. Wu, and M. Leung, "A review on biodiesel production using catalyzed transesterification," Applied energy, vol. 87, no. 4, pp. 1083-1095, 2010.

[24] T. Kanoh, H. Iwabuchi, Y. Hoshida, J. Yamada, T. Hikosaka, A. Yamazaki, Y. Hatta, and H. Koide, "Analyses of electro-chemical characteristics of palm fatty acid esters as insulating oil," in 2008 IEEE International Conference on Dielectric Liquids, 2008.

[25] A. Röttig, L. Wenning, D. Bröker, and A. Steinbüchel, "Fatty acid alkyl esters: perspectives for production of alternative biofuels," Applied microbiology and biotechnology, vol. 85, no. 6, pp. 1713-1733, 2010.

[26] L. Meher, D.V. Sagar, and S. Naik, "Technical aspects of biodiesel production by transesterification - a review," Renewable and sustainable energy reviews, vol. 10, no. 3, pp. 248-268, 2006.

[27] U. Schuchardt, R. Sercheli, and R.M. Vargas, "Transesterification of vegetable oils: a review," Journal of the Brazilian Chemical Society, vol. 9, no. 3, pp. 199210, 1998.
[28] Y. Kasahara, M. Kato, S. Watanabe, M. Iwahashi, R. Wakamatsu, T. Suzuki, A. Kanetani, T. Kano, and T. Tamura, "Consideration on the relationship between dielectric breakdown voltage and water content in fatty acid esters," Journal of the American Oil Chemists' Society, vol. 89, no. 7, pp. 1223-1229, 2012.

[29] S. C. Cermak, G. Biresaw, T. A. Isbell, R. L. Evangelista, S.F. Vaughn, and R. Murray, "New crop oils - Properties as potential lubricants," Industrial Crops and Products, vol. 44, pp. 232-239, 2013.

[30] M.J. Ramos, C.M. Fernández, A. Casas, L. Rodríguez, and Á. Pérez, "Influence of fatty acid composition of raw materials on biodiesel properties," Bioresource technology, vol. 100, no. 1, pp. 261-268, 2009.

[31] A. Kamal-Eldin, and R. Andersson, "A multivariate study of the correlation between tocopherol content and fatty acid composition in vegetable oils," Journal of the American Oil Chemists' Society, vol. 74, no. 4, pp. 375-380, 1997.

[32] W. Neff, T. Mounts, W. Rinsch, H. Konishi, and M. El-Agaimy, "Oxidative stability of purified canola oil triacylglycerols with altered fatty acid compositions as affected by triacylglycerol composition and structure," Journal of the American Oil Chemists' Society, vol. 71, no. 10, pp. 1101-1109, 1994.

[33] D. Martin, and Z. Wang, "A comparative study of the impact of moisture on the dielectric capability of esters for large power transformers," in 2006 IEEE Conference on Electrical Insulation and Dielectric Phenomena, 2006.

[34] Y. Du, A.V. Mamishev, B.C. Lesieutre, M. Zahn, and S.-H. Kang, "Moisture solubility for differently conditioned transformer oils," IEEE Transactions on Dielectrics and Electrical Insulation, vol. 8, no. 5, pp. 805-811, 2001.

[35] D. Martin, N. Lelekakis, W. Guo, and Y. Odarenko, "Further studies of a vegetable-oil-filled power transformer," IEEE Electrical Insulation Magazine, vol. 27, no. 5, pp. 6-13, 2011.

[36] H. Borsi, and E. Gockenbach, "Properties of ester liquid Midel 7131 as an alternative liquid to mineral oil for transformers," in IEEE International Conference on Dielectric Liquids, 2005. ICDL 2005., 2005.

[37] D. Martin, I. Khan, J. Dai, and Z. Wang, “An overview of the suitability of vegetable oil dielectrics for use in large power transformers," in TJ/H2b Euro TechCon Conf., Chester, UK, 2006.

[38] R. Liao, J. Hao, G. Chen, Z. Ma, and L. Yang, “A comparative study of physicochemical, dielectric and thermal properties of pressboard insulation impregnated with natural ester and mineral oil," IEEE Transactions on Dielectrics and Electrical Insulation, vol. 18, no. 5, pp. 1626-1637, 2011.

[39] D. Martin, and Z. Wang, "Statistical analysis of the AC breakdown voltages of ester based transformer oils," IEEE Transactions on Dielectrics and Electrical 
Insulation, vol. 15, no. 4, pp. 1044-1050, 2008.

[40] X. Wang, and Z. Wang, "Particle effect on breakdown voltage of mineral and ester based transformer oils," in 2008 Annual Report Conference on Electrical Insulation and Dielectric Phenomena, 2008.

[41] A. Tekin, and E.G. Hammond, "Factors affecting the electrical resistivity of soybean oil methyl ester," Journal of the American Oil Chemists' Society, vol. 77, no. 3, pp. 281-283, 2000.

[42] R. Dunn, and M. Bagby, "Low-temperature properties of triglyceride-based diesel fuels: transesterified methyl esters and petroleum middle distillate/ester blends," Journal of the American Oil Chemists' Society, vol. 72, no. 8, pp. 895-904, 1995.

[43] A. Srivastava, and R. Prasad, "Triglycerides-based diesel fuels," Renewable and sustainable energy reviews, vol. 4, no. 2, pp. 111-133, 2000.

[44] A. S. Ramadhas, S. Jayaraj, and C. Muraleedharan, "Biodiesel production from high FFA rubber seed oil," Fuel, vol. 84, no. 4, pp. 335-340, 2005.

[45] T. Oommen, C. Claiborne, E. Walsh, and J. Baker, "A new vegetable oil based transformer fluid: development and verification," in Electrical Insulation and Dielectric Phenomena, 2000 Annual Report Conference on, 2000.

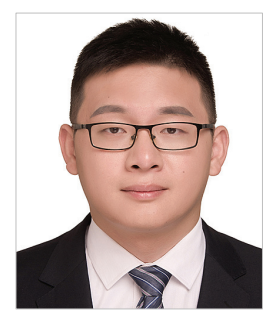

Hui Yu He received his B.Sc. degree in chemistry from Wuhan University in 2008. He is presently a Ph.D. candidate in College of Chemistry and Molecular Science, Wuhan University. He has been engaged in research of insulating oil.

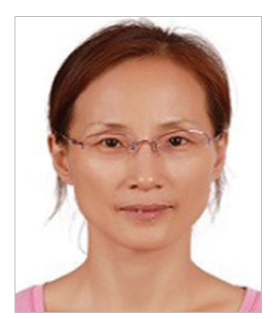

Ping Yu She received her Ph.D. degree in fluid machinery and engineering from Wuhan University. She is presently a professor at the College of Chemistry and Molecular Science, Wuhan University, and the dean of application chemistry department. Her main topics of interest are the separation and purification technology, water and oil analysis.

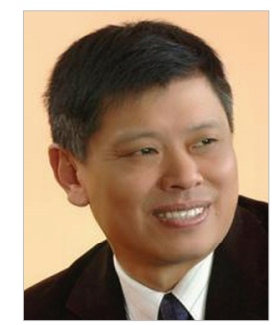

fine chemicals.
Yunbai Luo He received his Ph.D. degree in chemical engineering from Tientsin University. He is presently a professor at College of Chemistry and Molecular Science, Wuhan University. His main topics of interest are chemical separation, chemical and environmental engineering, insulation materials, and 